\title{
Clotrimazole reduces endometriosis and the estrogen concentration by downregulating aromatase
}

\author{
Daniel Escorsim Machado ${ }^{1,2}$, Jéssica Alessandra-Perini ${ }^{1,2}$, Erika Menezes de Mendonça1,3, \\ Marllow Caetano Claudino ${ }^{1}$, Luiz Eurico Nasciutti ${ }^{2}$, Mauro Sola-Penna ${ }^{4}$, Patrícia Zancan ${ }^{5}$ and \\ Jamila Alessandra Perini ${ }^{1,3}$ \\ ${ }^{1}$ Laboratório de Pesquisa de Ciências Farmacêuticas (LAPESF), Unidade de Farmácia, Centro Universitário Estadual \\ da Zona Oeste (UEZO), Rio de Janeiro, Rio de Janeiro, Brasil, ${ }^{2}$ Programa de Ciências Morfológicas (PCM), Instituto \\ de Ciências Biomédicas (ICB), Universidade Federal do Rio de Janeiro (UFRJ), Rio de Janeiro, Rio de Janeiro, Brasil, \\ 3 Programa de Pós-Graduação em Saúde Pública e Meio Ambiente, Escola Nacional de Saúde Pública (ENSP), \\ Fundação Osvaldo Cruz (Fiocruz), Rio de Janeiro, Rio de Janeiro, Brasil, ${ }^{4}$ Laboratório de Enzimologia e Controle do \\ Metabolismo (LabECoM), Departamento de Biotecnologia Farmacêutica (BioTecFar), Faculdade de Farmácia, \\ Universidade Federal do Rio de Janeiro (UFRJ), Rio de Janeiro, Rio de Janeiro, Brasil and ${ }^{5}$ Laboratório de \\ Oncobiologia Molecular (LabOMol), Departamento de Biotecnologia Farmacêutica (BioTecFar), Faculdade de \\ Farmácia, Universidade Federal do Rio de Janeiro (UFRJ), Rio de Janeiro, Rio de Janeiro, Brasil
}

Correspondence should be addressed to D E Machado; Email: danielescorsim@yahoo.com.br

\begin{abstract}
This study aimed to analyse the effects of clotrimazole (CTZ) on estrogen production pathway in endometriosis progression. Experimental endometriosis was induced by autologous transplantation in female Wistar rats, and then the rats were treated with clotrimazole $(200 \mathrm{mg} / \mathrm{kg})$ or vehicle, both orally and intraperitoneally, for 15 consecutive days. Serum estrogen levels and vaginal smear analyses were performed and ER $\alpha$ (estrogen receptor alpha) and CYP19 (cytochrome P450 aromatase) levels in the endometriotic lesions were analysed morphologically and immunohistochemically. The clotrimazole group presented a reduction in serum estrogen levels, which were not influenced by the estrous cycle of the animals. The expression of ER $\alpha$ and CYP19 in endometriotic lesions was also reduced in the clotrimazole group compared to the control group. Moreover, clotrimazole treatment decreased the size of the lesions, as confirmed by histological examination, which showed glandular atrophy for both routes of administration. These results suggest that clotrimazole interferes with the estrogen production pathway by downregulating CYP19 and, therefore, reducing serum estrogen levels. Thus, the drug decreases endometriotic lesion size and consequently disease progression.

Reproduction (2020) 159 779-786
\end{abstract}

\section{Introduction}

Endometriosis is an estrogen-dependent disease, characterized by the presence of endometrial tissue outside the uterine cavity (Giudice 2010). Its prevalence is estimated to be $10-15 \%$ in women of reproductive age (Buck Louis et al. 2011, Acién \& Velasco 2013), and it is often associated with clinical symptoms including chronic pelvic pain, dysmenorrhea, dyspareunia and infertility (Fauconnier et al. 2013). The prevalence of endometriosis increases to $35-50 \%$ in infertile women and is considered one of the most common gynaecological diseases (Buck Louis et al. 2011, Acién \& Velasco 2013).

Some risk factors such as age, family history, alcohol consumption, smoking and primarily the high level of estrogen are associated with the development of endometriosis (Vigano et al. 2004, Parazzini et al. 2017, Hemmert et al. 2018). Several studies have demonstrated that lesion growth is related to the action estrogen, while hormone reduction due to menopause, pregnancy or pharmacological suppression of endogenous secretion usually reduces endometriosis (Huhtinen et al. 2012, Vercellini et al. 2016, Marie-Scemama et al. 2019). Naqvi et al. (2014) showed that a selective estrogen receptor modulator (BZA) inhibits the action of estrogen on endometrial cell proliferation in an experimental model of endometriosis, confirming that estrogen supports cellular proliferation in endometriosis (Naqvi et al. 2014).

One of the most important pathways responsible for the increased estrogen levels in patients with endometriosis is associated with expression of aromatase enzyme (Mori et al. 2018), a CYP19 gene product that is part of the 
cytochrome P450 family. Cytochrome P450 aromatase (CYP19A1) catalyses the conversion of testosterone and androstenedione to estradiol (E2) and estrone (E1), respectively, increasing estrogen production and endometriosis progression (Mori et al. 2018).

The current pharmacological treatments for endometriosis, which include the use of gonadotropinreleasing hormone $(\mathrm{GnRH})$ agonists, progesterone oral contraceptives and aromatase inhibitors, work by suppressing ovarian function (Lindsay et al. 2015, Vercellini et al. 2016). However, these treatments are associated with undesirable side effects, such as a weight gain, muscle cramps, acne, seborrhea, depression, flushing, urogenital atrophy, loss of libido and bone mass decrease (Vercellini et al. 2009, Lindsay et al. 2015, Becker et al. 2017). Moreover, women who want to become pregnant cannot use hormonal contraceptives for endometriosis treatment (Bedaiwy et al. 2017, Mori et al. 2018, Piccinato et al. 2018). Despite the drug treatment options, they are associated with many side effects, and surgery is still the gold standard therapeutic approach (Kho \& Abrão 2012). Therefore, identifying effective drug therapies, alone or in combination, with fewer adverse effects is an essential step to improve endometriosis management

Clotrimazole (CTZ) is an antifungal that is widely used in clinical practice to treat Candida infection and other fungal infections (Crowley \& Gallagher 2014). This drug is effective in controlling tumour progression by interfering with cancer cell metabolism and proliferation (Marcondes et al. 2010, 2015, Furtado et al. 2012, 2015). Recently, our group showed that CTZ is a promising novel pharmacological treatment for endometriosis due to its anti-inflammatory and antiangiogenic properties and that it significantly decreases the growth and size of endometriotic implants (Machado et al. 2018). Interestingly, CTZ has been demonstrated to inhibit CYP19A1 in humans, through its antiproliferative effects in human breast cancer (Trösken et al. 2004). On the other hand, the upregulation of CYP19A1 increases estrogen levels, which are correlated with increased levels of prostaglandin E2 $\left(\mathrm{PGE}_{2}\right)$ and other inflammatory mediators (Bulun et al. 2001) that are involved in the pathogenesis of endometriosis (Machado et al. 2010, 2016, 2018, Mattos et al. 2019).

Therefore, in the present study, we investigated the effects of CTZ on the estrogen production pathway, specifically the aromatase enzyme, and consequently on estrogen levels in an experimental model of endometriosis.

\section{Materials and methods \\ Determination and cyclicity of the estrous cycle}

The estrous cycle was monitored daily by vaginal smears collected using sterile swabs and stained with a Papanicolaou kit according to the manufacturer's instructions (QEEL Química Especializada Erich Ltda, São Paulo, SP, Brazil). The stages were identified by microscopic examination according to cytological findings as follows: proestrus, nucleated cells; estrus, cornified cells; metestrus, cornified cells plus leucocytes; and diestrus, leucocytes (Cora et al. 2015). Only rats that showed three consecutive 5-day estrous cycles with normal progression and synchronicity of all stages were used.

\section{Experimental model of endometriosis}

Animals were treated in accordance with protocols approved by the State University of West Zone (UEZO), with guidelines from the Ethics Commission on Animal Use (CEUA 009/2019). Female Wistar rats (8-weeks old and 200 g) were used to test the effects of CTZ in experimental endometriosis as previously described (Machado et al. 2010, 2016, Machado et al. 2018, Mattos et al. 2019).

Animals were anaesthetized (ketamine and xylazine), the abdomen was opened and one uterine horn was removed; the endometrium was exposed and split longitudinally into two pieces and one piece was implanted on each side of the ventral abdominal peritoneal wall with sutures. The abdomen was closed, and the animals were allowed to recover from anaesthesia.

\section{Clotrimazole treatment}

After 15 days, ventral midline laparotomy was performed to evaluate the viability and size (length $x$ width) of the endometrial explants. The rats were randomly divided into four groups: groups treated with CTZ $(200 \mathrm{mg} / \mathrm{kg}$ body weight, clotrimazole, Sigma Chemicals 129 Co.) diluted in sunflower oil, by (1.) gavage $(n=15)$ or (2.) intraperitoneal injection $(n=10)$; and control groups that received sunflower oil as vehicle by (3.) gavage $(n=15)$ or (4.) intraperitoneal injection $(n=10)$. All treatments were administered daily for 15 consecutive days. Body weight was measured at the start of treatment (day zero, D0), on day 7 of treatment (D7) and on the last day of treatment (D15), when the animals were killed by anaesthetic overdose. The endometriotic lesions were counted, weighed, measured (length $\times$ width) and collected for histological and immunohistochemical analysis. Blood samples were collected for the analysis of serum estrogen levels.

\section{Histology, immunohistochemistry and morphometric analysis}

Peritoneal lesions were fixed in buffered formalin, embedded in paraffin and cut into $4-\mu \mathrm{m}$-thick sections. Some of the sections were stained with Harris hematoxylin and eosin $(\mathrm{HE})$, and the other sections were placed on silane-treated slides and incubated overnight with the following antibodies: a MAB against ER $\alpha$ (sc-8005, Santa Cruz Biotechnology) and a polyclonal antibody against CYP19A1 (ab-18995, Abcam discover more, Abcam) (both at 1:100 dilution). Then, the staining was visualized using a LSAB2 Kit HRP (DakoCytomation) with diaminobenzidine (3,3'-diaminobenzidine 
tablets; Sigma) as the chromogen, and the sections were counterstained with hematoxylin. For each case, negative control slides were incubated with antibody vehicle or no immune rabbit or mouse serum.

All samples were evaluated by two blinded observers under a light microscope (Nikon) connected to a digital camera (Coolpix 990; Nikon) at a magnification of $400 \times$. Sections immunostained (ten fields) with each antibody from each specimen were randomly chosen and captured. Using highquality captured images $(2048 \times 1536$ pixel buffer $)$ and the Image Pro Plus 4.5.1 program (Media Cybernetics, Silver Spring, MD, USA), the samples were quantified. Histological scores $(\mathrm{H})$ for $\mathrm{ER} \alpha$ and CYP19A1 were calculated using the formula $\mathrm{H}=\Sigma \mathrm{P} i$, where $i$ is the intensity ranging from 0 (negative cells) to 3 (strongly stained cells) and $P$ is the percentage of stained cells for each given $i$, with $\mathrm{P}$ values of $1,2,3,4$ and 5 indicating $85 \%$ and $100 \%$ positively-stained cells as previously described (Machado et al. 2016, 2018, Mattos et al. 2019). The staining results are expressed as the mean \pm S.D.

\section{Estrogen levels}

Blood samples were taken at three different experimental stages (days: D-15, D0 and D15) and centrifuged at $1811 \mathrm{~g}$ for 10 min to obtain the serum for hormonal profile analysis. The serum estrogen levels were assayed in duplicate using an ELISA kit manufactured by Diagnostics Biochem Canada Inc. (DBC) and were calculated from standard curves generated by an automatic plate reader (Spectra Max; Molecular Devices, Sunnyvale, Calif) controlled by SoftMax software (Molecular Devices).

\section{Statistical analysis}

The data are expressed as the mean \pm S.D., and statistical analyses were performed with Student's $t$-test. For morphometric analysis of ER $\alpha$ and CYP19A1, statistical calculations were carried out using the Stat Xact-5 software program (CYTEL Software Corporation, Cambridge, MA). Significance for all statistical comparisons was set at $P<0.05$.

\section{Results}

\section{Serum estrogen levels are reduced by CTZ}

Endometriosis model rats were orally treated with CTZ (200 mg/kg of body weight, by gavage) or the same volume of sunflower oil used as vehicle (control group) for 15 consecutive days. To characterize the estrous cycle of the animals, vaginal smear analysis was performed daily. On day 15, all rats were in the estrous phase, which was confirmed by the predominance of anucleated cornified cells (Fig. 1A and B). On days 0 (Fig. 1C and D) and 15 (Fig. 1E and F), nucleated cells and a predominance of leukocytes were observed in all animals, indicating the diestrus phase. In addition, serum estrogen levels were quantified at the different experimental stages. On days 15 (Fig. 1G) and 0 (Fig. 1H), serum estrogen levels were in the normal range in both groups (control and CTZ). However, after treatment, a significant reduction in serum estrogen levels was observed only in the CTZ group (Fig. 1I). This result allows us to conclude that the reduction in estrogen was caused by $\mathrm{CTZ}$, not by the estrous cycle of the animals.

\section{CTZ suppresses estrogen receptor $\alpha$ in endometriotic lesions}

Estrogen upregulates the expression of estrogen receptor $\alpha(E R \alpha)$ in different tissues (Liu \& Shi 2015, Uebi et al. 2015). Therefore, we assessed the expression of $E R \alpha$ in endometriotic lesions to evaluate the cellular effect of

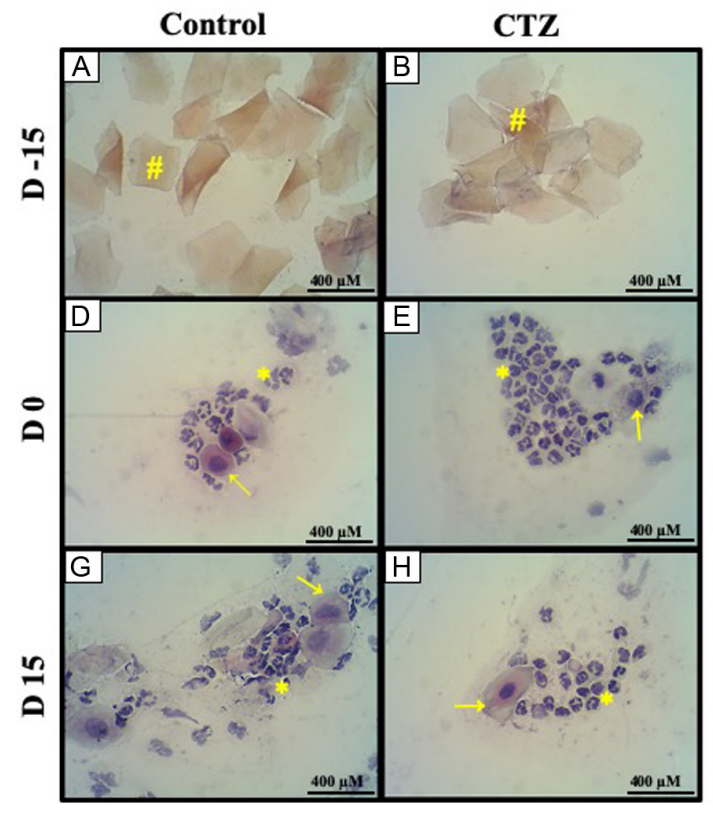

https://rep.bioscientifica.com
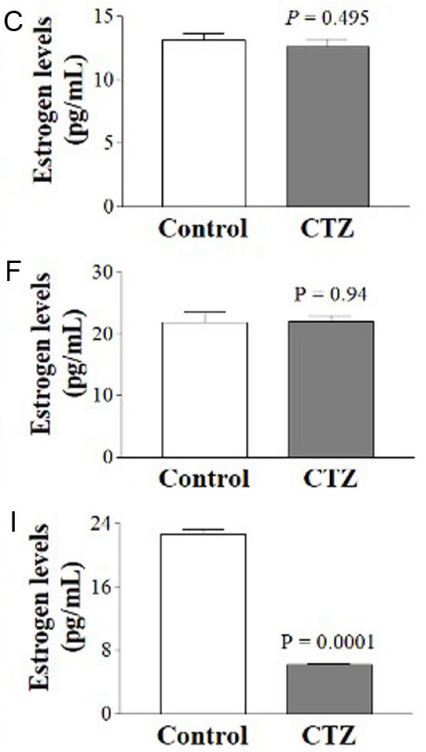

Figure 1 Estrogen is reduced by CTZ. Vaginal smears from (A, B, C, D, E and $F)$ and estrogen serum levels $(\mathrm{G}, \mathrm{H}$ and $\mathrm{I})$ in rats at different times of the experiment. Anucleated cornified cells (\#) were predominant on day 15 indicating the estrous phase. On days 0 and 15 , the diestrus phase was confirmed by the presence of nucleated cells $(\rightarrow)$ and a predominance of leukocytes $(*)$. A reduction in the serum estrogen concentration was observed only after treatment with CTZ $(P<0.05$, Student's $t$-test). 
decreased estrogen levels. Indeed, treatment with CTZ (Fig. 2C and D) diminished the immunoreactivity of the endometriotic lesions to anti-ER $\alpha$ compared to that in controls treated with vehicle, in which prominent stromal markings were observed (Fig. 2A and B). Quantification of the images confirmed a 35\% reduction in the expression of ER $\alpha$ in CTZ-treated samples as compared to control samples (Fig. 2E; $P<0.05$, Student's t-test; $n=15$ ).

\section{CTZ treatment downregulates CYP19A1}

This same treatment drastically downregulated the expression of CYP19A1, as analysed by immunohistochemical analysis of the endometriotic lesions (Fig. 3A and B for control group and Fig. 3C and D for CTZ group). Histomorphometric analysis of the images revealed a greater than $80 \%$ reduction in the expression of CYP19A1 in the animals upon CTZ treatment (Fig. 3E; $P<0.05$, Student's $t$-test; $n=15$ ).
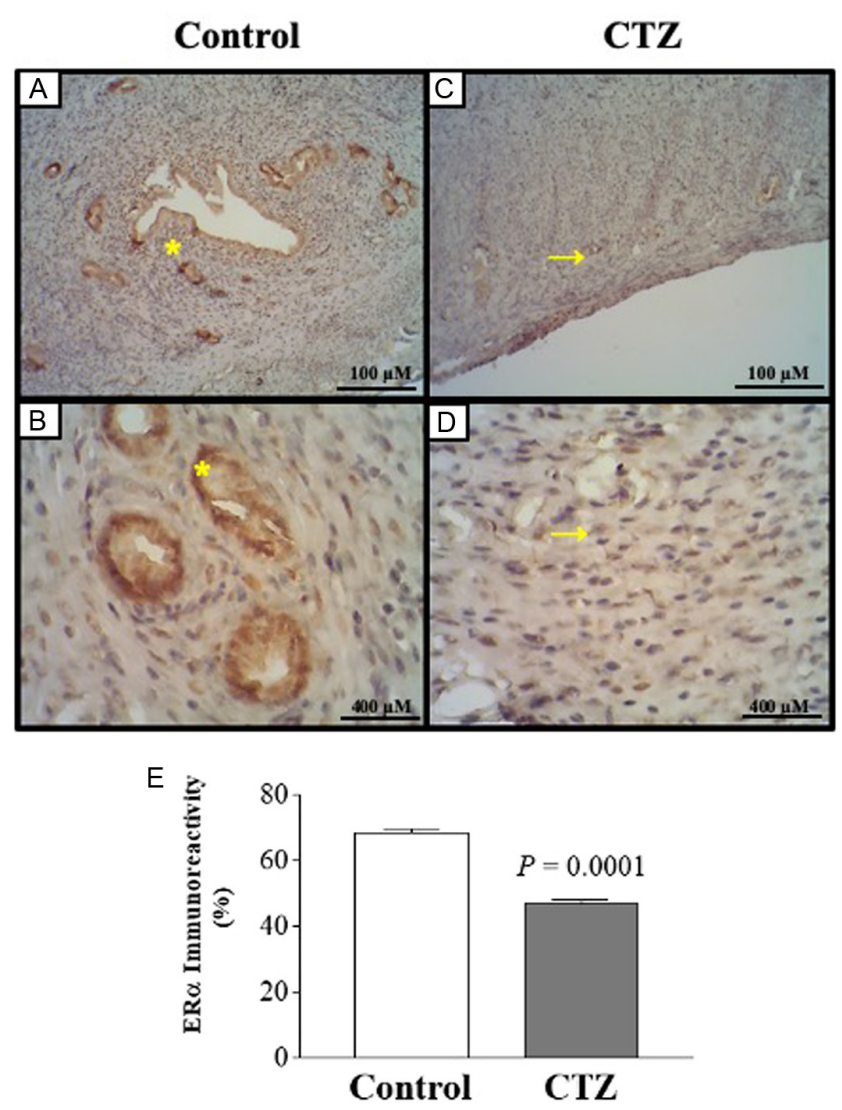

Figure 2 CTZ suppresses the alpha estrogen receptor in endometriosis. Immunohistochemical staining for ER $\alpha$ in endometriotic lesions (A, B, C and D). There was greater staining for $E R \alpha$ in the control group (A and $B)$, which was detected predominantly in the stroma $(*)$, primarily around the glands CTZ treated endometriotic lesions (C and D), exhibiting a significant decrease in reaction intensity $(\rightarrow)$, which was confirmed by morphometric analysis (E).

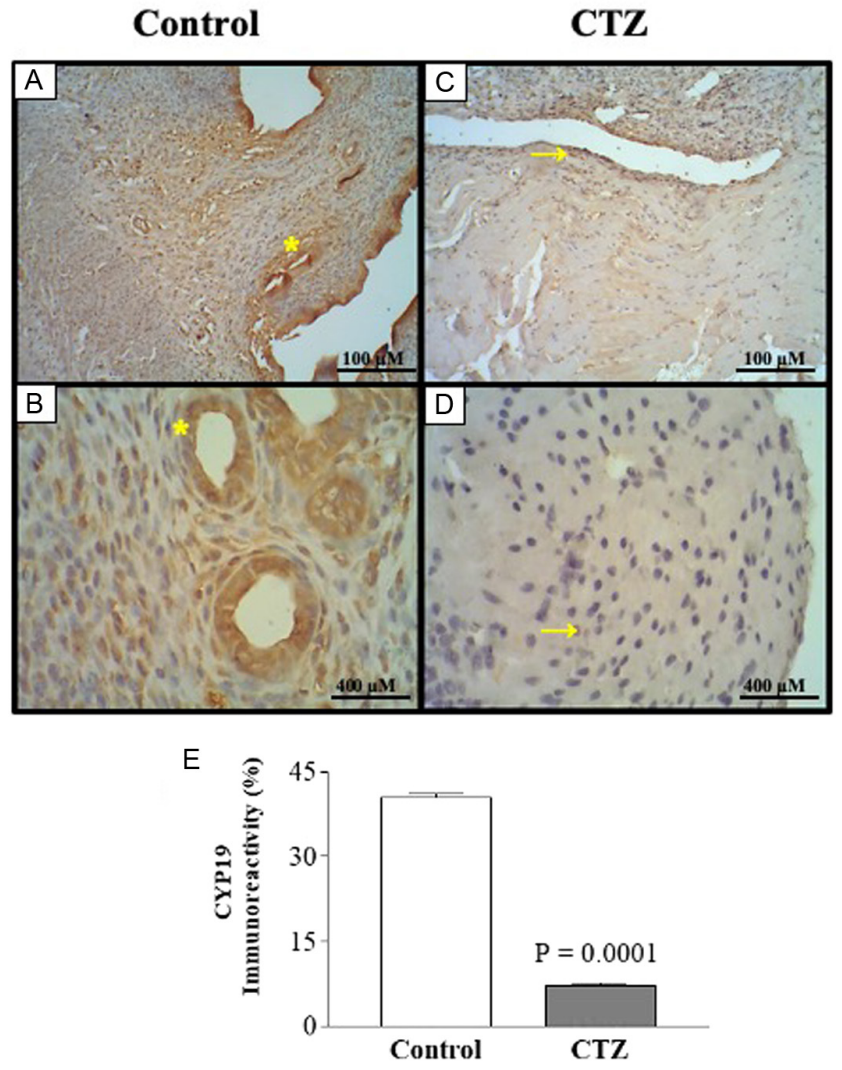

Figure 3 Aromatase enzyme is reduced by CTZ treatment in endometriosis in vivo. Immunohistochemical staining for CYP19 in endometriotic lesions (A, B, C and D). There was greater labelling for CYP19 in the control group $\left(^{*}\right)(A$ and $B)$ than in the group treated with CTZ $(\rightarrow)$ (C and D), as confirmed by morphometric analysis (E) $(P<0.05$, Student's $t$-test).

\section{CTZ treatment improves endometriotic lesions}

After 15 days of autologous transplantation (day 0 ), endometriotic lesions were cystic and well vascularized in all animals (Fig. 4A, B, C and D). At the end of treatments (day 15), the animals in the control group still had cystic lesions (Fig. 4E and F). However, the maintenance, growth and implant size of the lesions were significantly decreased regardless of whether the drug was administered intraperitoneally or by gavage (Fig. 4G and H). The viability of the control group lesions was confirmed by histopathological analysis, which showed the presence of glands and stroma, which are characteristic of endometrial tissue (Fig. $4 \mathrm{I}$ and J). Atrophy and regression of lesions in the CTZ-treated groups were also confirmed by histological analysis (Fig. 4K and L). Furthermore, CTZ treatment significantly diminished the lesion size in the orally and intraperitoneally treated groups from day 0 to day 15 (Table 1 ). Moreover, there were no significant differences in endometriotic lesion growth or size between the intraperitoneally and orally treated groups (Table 1). 


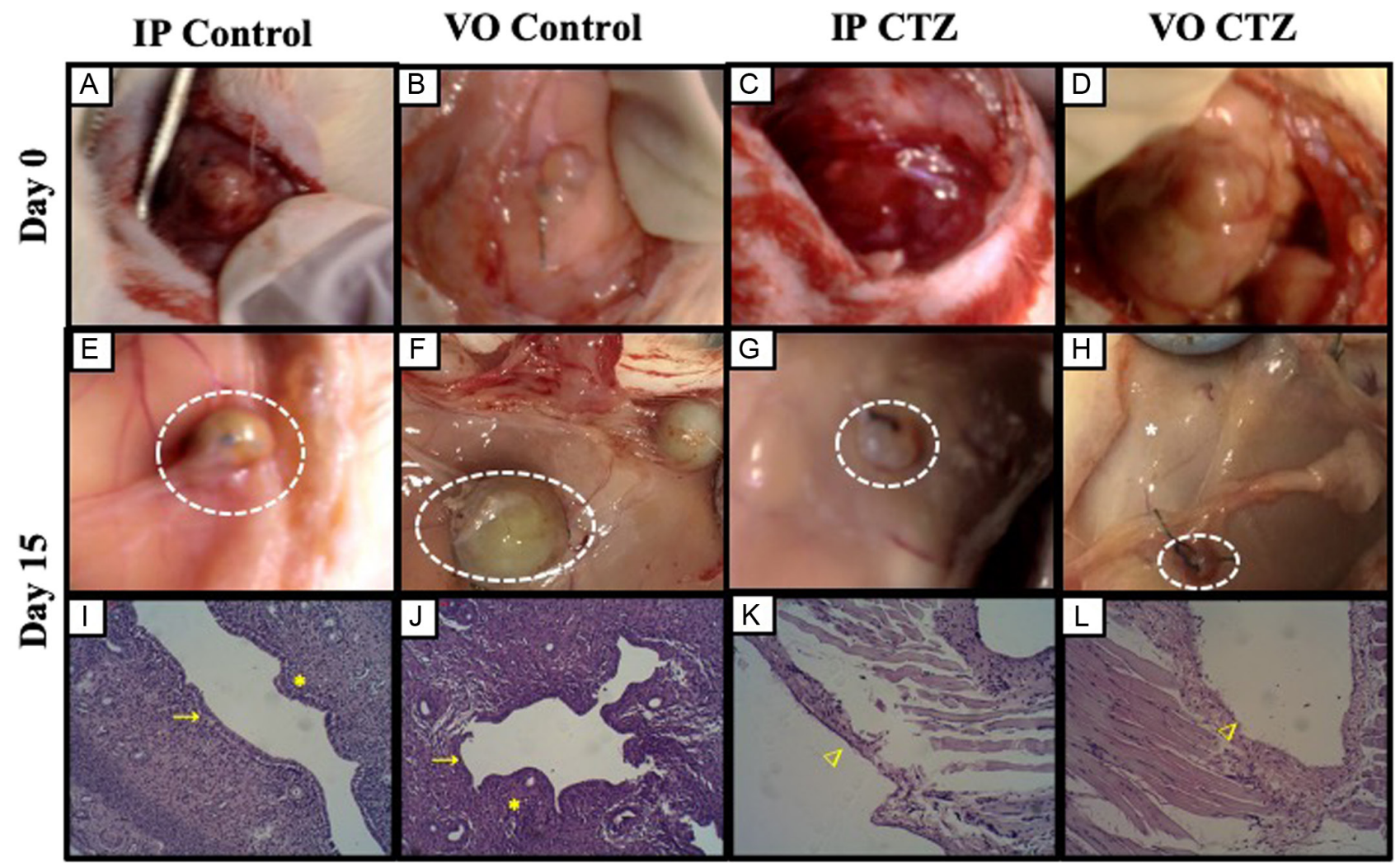

Figure 4 CTZ decreases endometriotic lesion growth. Endometriotic lesion controls (A, B and E, F) and models treated with CTZ (C, D and G, H) intraperitoneally or orally showed hematoxylin and eosin staining ( $\mathrm{l}, \mathrm{J}, \mathrm{K}$ and $\mathrm{L}$ ). Control endometriosis models showed the presence of endometrial glands (arrows) and stromal cells $(*)$. In the treated animals, the maintenance of the lesions was suppressed, and prominent atrophy of the glands was observed (arrowhead). Magnification, 200x.

\section{Discussion}

Approximately 176 million women of reproductive age are affected by endometriosis worldwide, and this condition causes severe pain and disabilitiy (World Bank 2010). Although highly expensive, surgery is still the principal treatment for the disease due to several undesirable side effects of available pharmacological treatments (Kho \& Abrão 2012). However, new drugs with minimal side effects are being still pursued by many groups aiming to improve patient quality of life. In this context, experimental models of endometriosis induced by autologous transplantation have been used for the evaluation of new therapies for the treatment of endometriosis (Grümmer 2006, Machado et al. 2010, 2016, 2018, Mattos et al. 2019). As endometriosis is an estrogen-dependent disease, drugs that interfere with estrogen production and/or the effects of estrogen are strong candidates for pharmacological therapy for endometriosis (Lindsay et al. 2015, Mori et al. 2018).

Azole derivatives are widely used in gynaecology to treat fungal infections, and CTZ is the most commonly used drug for this purpose (Zhou et al. 2016). The antifungal action of these drugs is exerted by blocking ergosterol synthesis through interference with the fungal cytochrome P450 complex (Vanden Bossche et al. 1989). It has also been shown that different azole derivatives interfere with purified recombinant human CYP19A1 (Trösken et al. 2004), a component of the cytochrome P450 complex and the key enzyme in the biosynthetic pathway of estrogens (Mori et al. 2018). However, few studies have tested azole derivatives for endometriosis treatment (Lu et al. 2010, Jouhari et al. 2018, Machado et al. 2018), and our study is the only one that has evaluated orally administered CTZ (Machado et al. 2018). Oral administration is the safest and most convenient way to administer medications. In addition, the oral formulations currently available on the market are safe, easy to administer and reach desired therapeutic concentrations, making the oral route an ideal choice (Kuper 2008).

In the current work, we demonstrated that, compared to control, endometriosis model rats that received CTZ orally for 15 consecutive days showed regression of endometriotic lesions and that this effect was equivalent to that observed in rats that received intraperitoneal injection of the drug. These results confirm our previous statement that CTZ is effective in treating endometriosis (Machado et al. 2018) and that the oral administration of CTZ is as effective as intraperitoneally injected 


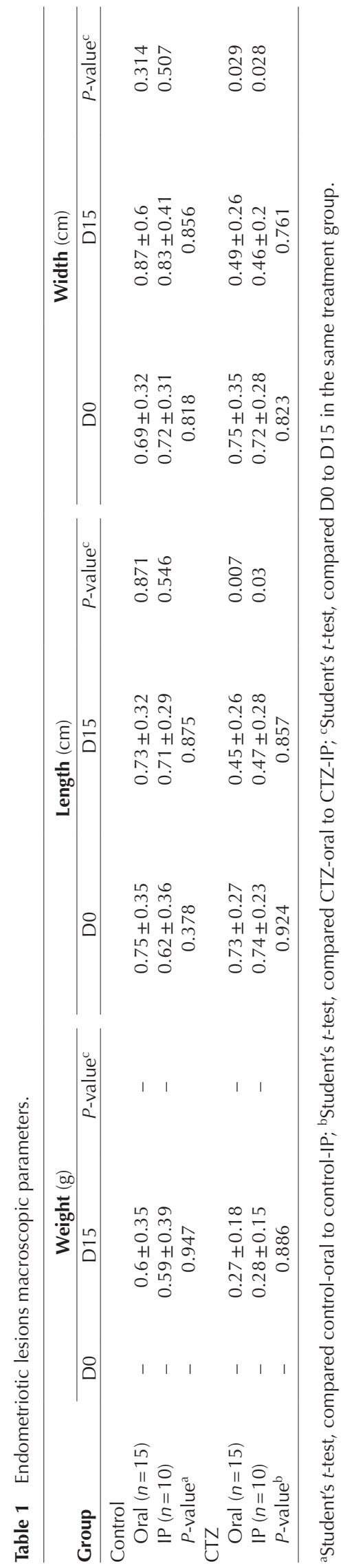

CTZ. Our results also support the potential internal use of CTZ, which is widely used in gynaecology as a topic pharmaceutical, as an oral medication to treat endometriosis. Furthermore, we previously reported that there is no evidence that CTZ is toxic at the dose administered, as determined based on body weight and food consumption compared that those of control animals.

Mechanistically, we previously observed that CTZ attenuates the pro-inflammatory state in endometriotic lesions, which we believe suggests the effectiveness of the drug for treating endometriosis (Machado et al. 2018). In the current work, we found evidence demonstrating that CTZ downregulates CYP19A1 in endometriotic lesions. This result is in accordance with the findings that different azole derivatives, including CTZ, inhibit CYP19A1 in vitro (Trösken et al. 2004), and extends these findings to in vivo models. Targeting CYP19A1 is a desirable strategy for controlling and treating endometriosis since this enzyme is directly responsible for estrogen synthesis (Lindsay et al. 2015, Mori et al. 2018). Indeed, our findings reveal that serum estrogen levels decrease in animals upon CTZ treatment, which is a good indicator of its effectiveness against endometriosis (Zhu et al. 2018). Moreover, our results show that CTZ promoted a significant reduction in the expression of $E R \alpha$, the primary estrogen receptor associated with the progression of endometriosis (Delvoux et al. 2009, Andersen et al. 2018). Indeed, estrogen signaling via ER $\alpha$ promotes the expression of this receptor in a positive feedback loop (Liu \& Shi 2015, Uebi et al. 2015). Moreover, CYP19A1 expression is also positively modulated by estrogen via ER $\alpha$ (Kinoshita \& Chen 2003). Although a large amount of estrogens can be supplied locally via CYP19A1, the combined action of steroid sulfatase (STS) and the enzyme estrogen sulfotransferase (SULT1E1) also represents an important pathway for estrogen production (Cornel et al. 2018). Clinically, patients with endometriosis present increased circulating estrogen levels, which has been associated with higher expression of $E R \alpha$ within endometriotic lesions, leading to disease progression (Delvoux et al. 2009, Huhtinen et al. 2012, Andersen et al. 2018). Therefore, we propose that the inhibition of CYP19A 1 by CTZ is responsible for reducing the estrogen concentration, which, in turn, downregulates the expression of $\mathrm{PGE}_{2}$ and $\mathrm{ER} \alpha$ (Fig. 5).

Converting drug doses from animal models to humans is a challenge due to differences in pharmacokinetics, metabolism and surface intestinal area, and this is a limitation of our study. However, these dose conversions may be possible by correcting for body surface area using an exponent factor of 0.33 (Nair \& Jacob 2016). In the present study, rats weighing approximately $200 \mathrm{~g}$ were used, which can be converted to an equivalent dose of 18 $\mathrm{mg} / \mathrm{kg}$ CTZ for adult humans weighing $70 \mathrm{~kg}$. This dose of CTZ $(20 \mathrm{mg} / \mathrm{kg})$ has already been administered orally 


\section{ENDOMETRIOSIS}

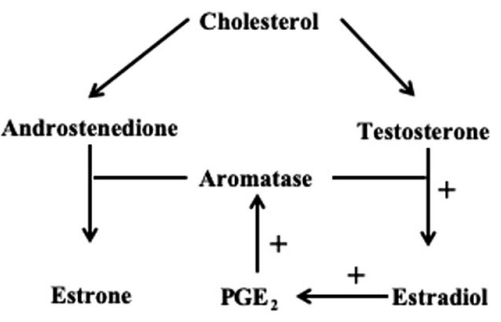

\section{ENDOMETRIOSIS}

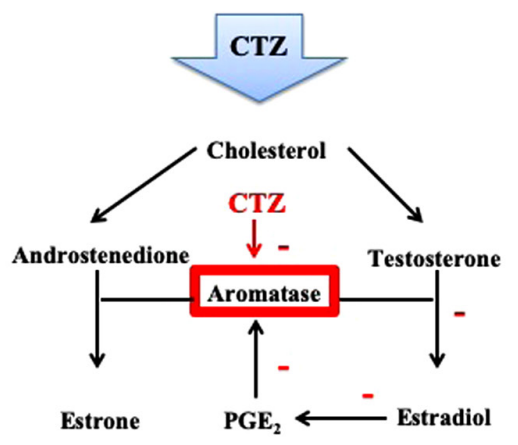

Figure 5 Proposed mechanism of action of CTZ in the estrogen pathway. In endometriosis, there is an increase in both circulating estrogen levels and estrogen levels in endometriotic lesions. This increase is due to increased expression of the aromatase enzyme, which may occur through an increase in the concentration of $\mathrm{PGE}_{2}$. CTZ decreases the concentrations of $\mathrm{PGE}_{2}$, which consequently decreases the expression of aromatase and estrogen production, resulting in disease regression. in a clinical trial involving 73 patients with rheumatoid arthritis for 12 weeks and no significant undesirable effects were observed (Dennison et al. 1990). Thus, future investigations are necessary to better understand the adverse effects of CTZ in endometriosis treatment.

\section{Conclusions}

In conclusion, CTZ is effective in inducing the regression of endometriosis lesions. This effectiveness is due to reduced levels of local and systemic estrogen, a hormone responsible for the progression of the disease, caused specifically by the downregulation CYP19A1. We believe that, in the future, it will be possible to carry out clinical tests based on these results and thus confirm CTZ as a new strategy for the treatment of endometriosis.

\section{Declaration of interest}

The authors declare that there is no conflict of interest that could be perceived as prejudicing the impartiality of the research reported.

\section{Funding}

This study was supported by the Brazilian agency Fundação Carlos Chagas Filho de Amparo à Pesquisa do Estado do Rio de Janeiro - FAPERJ, Fundação Ary Frauzino - Oncobiologia and Coordenação de Aperfeiçoamento de Pessoal de Nível Superior-CAPES, Brasil.

\section{Author contribution statement}

D E M, P Z and J A P performed conception and design of study. E M M, J A-P, M C C and D E M helped with all the experiments and designed the methodology. D E M, E M M, J A-P and J A P performed formal analysis and interpretation of data. D E M, E M M, J A-P and J A P wrote the original draft. LE N, M S P and P Z performed critical review and edited the manuscript for important intellectual content. D E M, P Z and J A P obtained funding and resources. All authors read and approved the final manuscript.

\section{References}

Acién P \& Velasco I 2013 Endometriosis: a disease that remains enigmatic. ISRN Obstetrics and Gynecology 2013 242149. (https://doi. org/10.1155/2013/242149)

Andersen CL, Boisen MM, Sikora MJ, Ma T, Tseng G, Suryawanshi S, Vlad A, Elishaev E, Edwards RP \& Oesterreich S 2018 The evolution of estrogen receptor signaling in the progression of endometriosis to endometriosis-associated ovarian cancer. Hormones and Cancer 9 399-407. (https://doi.org/10.1007/s12672-018-0350-9)

Becker CM, Gattrell WT, Gude K \& Singh SS 2017 Reevaluating response and failure of medical treatment of endometriosis: a systematic review. Fertility and Sterility 108 125-136. (https://doi.org/10.1016/j. fertnstert.2017.05.004)

Bedaiwy MA, Allaire C, Yong P \& Alfaraj S 2017 Medical management of endometriosis in patients with chronic pelvic pain. Seminars in Reproductive Medicine 35 38-53. (https://doi. org/10.1055/s-0036-1597308)

Buck Louis GM, Hediger ML, Peterson CM, Croughan M, Sundaram R, Stanford J, Chen Z, Fujimoto VY, Varner MW, Trumble A, et al. 2011 Incidence of endometriosis by study population and diagnostic method: the endo study. Fertility and Sterility 96 360-365. (https://doi. org/10.1016/j.fertnstert.2011.05.087)

Bulun SE, Yang S, Fang Z, Gurates B, Tamura M, Zhou J \& Sebastian S 2001 Role of aromatase in endometrial disease. Journal of Steroid Biochemistry and Molecular Biology 79 19-25. (https://doi.org/10.1016/ s0960-0760(01)00134-0)

Cora MC, Kooistra L \& Travols G 2015 Vaginal cytology of the laboratory rat and mouse: review and criteria for the staging of the estrous cycle using stained vaginal smears. Toxicologic Pathology 43 776-793. (https://doi. org/10.1177/0192623315570339)

Cornel KMC, Delvoux B, Saya T, Xanthoulea S, Konings GFJ, Kruitwagen RPFM, Bongers MY, Kooreman L \& Romano A 2018 The sulfatase pathway as estrogen supply in endometrial cancer. Steroids 139 45-52. (https://doi.org/10.1016/j.steroids.2018.09.002)

Crowley PD \& Gallagher HC 2014 Clotrimazole as a pharmaceutical: past, present and future. Journal of Applied Microbiology 117 611-617. (https://doi.org/10.1111/jam.12554)

Delvoux B, Groothuis P, D'Hooghe T, Kyama C, Dunselman G \& Romano A 2009 Increased production of 17-estradiol in endometriosis lesions is the result of impaired metabolism. Journal of Clinical Endocrinology and Metabolism 94 876-883. (https://doi.org/10.1210/jc.2008-2218)

Dennison WB, Loeser RF, Turner RA, Johnson JA \& Wells HB 1990 A double blind placebo controlled trial of low dose clotrimazole in rheumatoid arthritis. Journal of Rheumatology 17 1003-1007.

Fauconnier A, Staraci S, Huchon C, Roman H, Panel P \& Descamps P 2013 Comparison of patient- and physician-based descriptions of symptoms of endometriosis: a qualitative study: a qualitative study. Human Reproduction 28 2686-2694. (https://doi.org/10.1093/humrep/det310)

Furtado CM, Marcondes MC, Sola-Penna M, Souza MLS \& Zancan P 2012 Clotrimazole preferentially inhibits human breast cancer cell proliferation, viability and glycolysis. PLOS ONE 7 e30462. (https://doi. org/10.1371/journal.pone.0030462) 
Furtado CM, Marcondes MC, Carvalho RS, Sola-Penna M \& Zancan P 2015 Phosphatidylinositol-3-kinase as a putative target for anticanceraction of clotrimazole. International Journal of Biochemistry and Cell Biology 62 132-141. (https://doi.org/10.1016/j.biocel.2015.03.004)

Giudice LC 2010 Clinical practice. Endometriosis. New England Journal of Medicine 362 2389-2398. (https://doi.org/10.1056/NEJMcp1000274)

Grümmer R 2006 Animal models in endometriosis research. Human Reproduction Update 12 641-649. (https://doi.org/10.1093/humupd/ dml026)

Hemmert R, Schliep KC, Willis S, Peterson CM, Louis GB, Allen-Brady K, Simonsen SE, Stanford JB \& Byun SKR 2018 Modifiable life style factors and risk for incident endometriosis. Paediatric and Perinatal Epidemiology 33 19-25. (doi:10.1111/ppe.12516)

Huhtinen K, Desai R, Ståhle M, Salminen A, Handelsman DJ, Perheentupa A \& Poutanen M 2012 Endometrial and endometriotic concentrations of estrone and estradiol are determined by local metabolism rather than circulating levels. Journal of Clinical Endocrinology and Metabolism 97 4228-4235. (https://doi.org/10.1210/jc.2012-1154)

Jouhari S, Mohammadzadeh A, Soltanghoraee H, Mohammadi Z, Khazali S, Mirzadegan E, Lakpour N, Fatemi F, Zafardoust S, Mohazzab A, et al. 2018 Effects of silymarin, cabergoline and letrozole on rat model of endometriosis. Taiwanese Journal of Obstetrics and Gynecology $\mathbf{5 7}$ 830-835. (available at: http://creativecommons.org/licenses/by-nc-nd/ 4.0/) (https://doi.org/10.1016/j.tjog.2018.10.011)

Kho RM \& Abrão MS 2012 Ovarian remnant syndrome: etiology, diagnosis, treatment and impact of endometriosis. Current Opinion in Obstetrics and Gynecology 24 210-214. (https://doi.org/10.1097/ GCO.0b013e3283558539)

Kinoshita Y \& Chen S 2003 Induction of aromatase (CYP19) expression in breast cancer cells through a nongenomic action of estrogen receptor alpha. Cancer Research 63 3546-3555.

Kuper KM 2008 Text book of competence assessment tools for healthsystem pharmacies. In Intravenous to Oral Therapy Conversion, 4th ed., pp. 347-360. ASHP.

Lindsay SF, Luciano DE \& Luciano AA 2015 Emerging therapy for endometriosis. Expert Opinion on Emerging Drugs 20 449-461. (https:// doi.org/10.1517/14728214.2015.1051966)

Liu X \& Shi H 2015 Regulation of estrogen receptor $\alpha$ expression in the hypothalamus by sex steroids: implication in the regulation of energy homeostasis. International Journal of Endocrinology 2015949085. (https://doi.org/10.1155/2015/949085)

Lu Y, Nie J, Liu X, Zheng Y \& Guo SW 2010 Trichostatin A, a histone deacetylase inhibitor, reduces lesion growth and hyperalgesia in experimentally induced endometriosis in mice. Human Reproduction 25 1014-1025. (available at: http://humrep.oxfordjournals.org/Downloa ded) (https://doi.org/10.1093/humrep/dep472)

Machado DE, Berardo PT, Landgraf RG, Fernandes PD, Palmero C, Alves LM, Abrao MS \& Nasciutti LE 2010 A selective cyclooxygenase-2 inhibitor suppresses the growth of endometriosis with an antiangiogenic effect in a rat model. Fertility and Sterility 93 2674-2679. (https://doi. org/10.1016/j.fertnstert.2009.11.037)

Machado DE, Rodrigues-Baptista KC, Alessandra-Perini J, Soares de Moura R, Santos TA, Pereira KG, Marinho da Silva Y, Souza PJ, Nasciutti LE \& Perini JA 2016 Euterpe oleracea extract (açaí) is a promising novel pharmacological therapeutic treatment for experimental endometriosis. PLOSONE11 e0166059. (https://doi.org/10.1371/journal.pone.0166059)

Machado DE, Perini JA, de Mendonça EM, Branco JR, RodriguesBaptista KC, Alessandra-Perini J, Espíndola-Neto JM, dos Santos TA, Coelho WS, Nasciutti LE, et al. 2018 Clotrimazole is effective for the regression of endometriotic implants in Wistar rat experimental model of endometriosis. Molecular and Cellular Endocrinology 476 17-26. (https://doi.org/10.1016/j.mce.2018.04.005)

Marcondes MC, Sola-Penna M \& Zancan P 2010 Clotrimazole potentiates the inhibitory effects of ATP on the key glycolytic enzyme 6-phosphofructo-1-kinase. Archives of Biochemistry and Biophysics 497 62-67. (https://doi.org/10.1016/j.abb.2010.03.013)

Marcondes MC, Fernandes ACS, Itabaiana I, de Souza ROMA, SolaPenna M \& Zancan P 2015 Nanomicellar formulation of clotrimazole improves its antitumor action toward human breast cancer cells. PLoS ONE 10 e0130555. (https://doi.org/10.1371/journal.pone.0130555)
Marie-Scemama L, Even M, Joliniere JBDL \& Ayoubi JM 2019 Endometriosis and the menopause: why the question merits our full attention. Hormone Molecular Biology and Clinical Investigation 37 20180071. (https://doi. org/10.1515/hmbci-2018-0071)

Mattos RM, Machado DE, Perini JA, Alessandra-Perini J, Meireles da Costa NO, Wiecikowski AFDRO, Cabral KMDS, Takiya CM, Carvalho RS \& Nasciutti LE 2019 Galectin-3 plays an important role in endometriosis development and in a target to endometriosis treatment. Molecular and Cellular Endocrinology 486 1-10. (https://doi.org/10.1016/j. mce.2019.02.007)

Mori T, Ito F, Koshiba A, Kataoka H, Tanaka Y, Okimura H, Khan KN \& Kitawaki J 2018 Aromatase as a target for treating endometriosis. Journal of Obstetrics and Gynaecology Research 44 1673-1681. (https://doi. org/10.1111/jog.13743)

Nair AB \& Jacob S 2016 A simple practice guide for dose conversion between animals and human. Journal of Basic and Clinical Pharmacy 7 27-31. (https://doi.org/10.4103/0976-0105.177703)

Naqvi H, Sakr S, Presti T, Krikun G, Komm B \& Taylor HS 2014 Treatment with bazedoxifene and conjugated estrogens results in regression of endometriosis in a murine model. Biology of Reproduction 90121. (https://doi.org/10.1095/biolreprod.113.114165)

Parazzini F, Esposito G, Tozzi L, Noli S \& Bianchi S 2017 Epidemiology of endometriosis and its comorbidities. European Journal of Obstetrics, Gynecology, and Reproductive Biology 209 3-7. (https://doi. org/10.1016/j.ejogrb.2016.04.021)

Piccinato CA, Malvezzi H, Gibson DA \& Saunders PTK 2018 SULFATION PATHWAYS: Contribution of intracrine oestrogens to the aetiology of endometriosis. Journal of Molecular Endocrinology 61 T253-T270. (https://doi.org/10.1530/JME-17-0297)

Trösken ER, Scholz K, Lutz RW, Völkel W, Zarn JA \& Lutz WK 2004 Comparative assessment of the inhibition of recombinant human CYP19 (aromatase) by azoles used in agriculture and as drugs for humans. Endocrine Research 30 387-394. (https://doi.org/10.1081/erc-200035093)

Uebi T, Umeda M \& Imai T 2015 Estrogen induces estrogen receptor alpha expression and hepatocyte proliferation in the livers of male mice. Genes to Cells 20 217-223. (https://doi.org/10.1111/gtc.12214)

Vanden Bossche H, Marichal P, Gorrens J, Coene MC, Willemsens G, Bellens D, Roels I, Moereels H \& Janssen PA 1989 Biochemical approaches to selective antifungal activity. Focus on azole antifungals. Mycoses 32 (Supplement 1) 35-52. (https://doi.org/10.1111/j.1439-0507.1989. tb02293.x)

Vercellini P, Somigliana E, Vigano P, Abbiati A, Barbara G \& Crosignani PG 2009 Endometriosis: current therapies and new pharmacological developments. Drugs 69 649-675. (https://doi.org/10.2165/00003495200969060-00002)

Vercellini P, Buggio L, Berlanda N, Barbara G, Somigliana E \& Bosari S 2016 Estrogen-progestins and progestins for the management of endometriosis. Fertility and Sterility 106 1552.e2-1571.e2. (https://doi. org/10.1016/j.fertnstert.2016.10.022)

Vigano P, Parazzini F, Somigliana E \& Vercellini P 2004 Endometriosis: epidemiology and aetiological factors. Best Practice and Research: Clinical Obstetrics and Gynaecology 18 177-200. (https://doi. org/10.1016/j.bpobgyn.2004.01.007)

World Bank 2010 Population projection tables by country and group. (available at: http://go.worldbank.org/KZHE1CQFA0)

Zhou X, Li T, Fan S, Zhu Y, Liu X, Guo X \& Liang Y 2016 The efficacy and safety of clotrimazole vaginal tablet vs. oral fluconazole in treating severe vulvovaginal candidiasis. Mycoses 59 419-428. (https://doi. org/10.1111/myc.12485)

Zhu TH, Ding SJ, Li TT, Zhu LB, Huang XF \& Zhang XM 2018 Estrogen is an important mediator of mast cell activation in ovarian endometriomas. Reproduction 155 73-83. (https://doi.org/10.1530/REP-17-0457)

Received 21 October 2019

First decision 6 January 2020

Revised manuscript received 14 March 2020

Accepted 2 April 2020 